\title{
A Review of the Critical Shoulder Angle
}

\author{
Jeffrey Thompson D0*, J Tyler Enders DO, Michael DiVella DO, Richard McCormack MD and Charles Ruotolo MD \\ Department of Orthopedics, New York, USA
}

*Corresponding author: Jeffrey Thompson DO, Department of Orthopedics, New York, USA

Submission: 証 January 29, 2018; Published: 眥February 07, 2019

\section{Introduction}

Rotator cuff tears (RCT) are a complex pathology of the shoulder which may result from trauma or chronic degeneration and are often multifactorial in nature. The concept of mechanical impingement of the supraspinatus tendon underneath the acromion was first introduced by Armstrong [1] in 1949 and was later verified and popularized by Neer [2]. In 1986, Bigliani et al. [3]. identified three distinct acromial shapes and found the hooked type acromion to be the most strongly associated with rotator cuff pathology. By Banas et al. [4] described an increase in RCTs and subacromial disease with a decreasing lateral inclination angle of the acromion.

Nyffeler et al. [5] introduced the concept of the acromion index in 2006 when they found that patients with a larger lateral extension of the acromion had a significantly increased incidence of full-thickness RCT. The Critical Shoulder Angle (CSA) was introduced by Moor et al. [6] as a reliable method to measure the lateral projection of the acromion and was associated with both glenohumeral osteoarthritis and RCTs.

\section{Critical shoulder angle radiographic parameters}

Moor et al. [6] described the CSA as the measurement of an angle created by the inclination of the glenoid and the most lateral extension of the acromion on an AP radiograph. The CSA is formed with a line connecting the superior to the inferior most aspect of the glenoid and a second line extending from the inferior glenoid to the inferolateral aspect of the acromion. A true AP is captured with the arm in neutral position and a visible glenohumeral joint space with little to no overlap of the anterior and posterior glenoid rim (Figure 1).
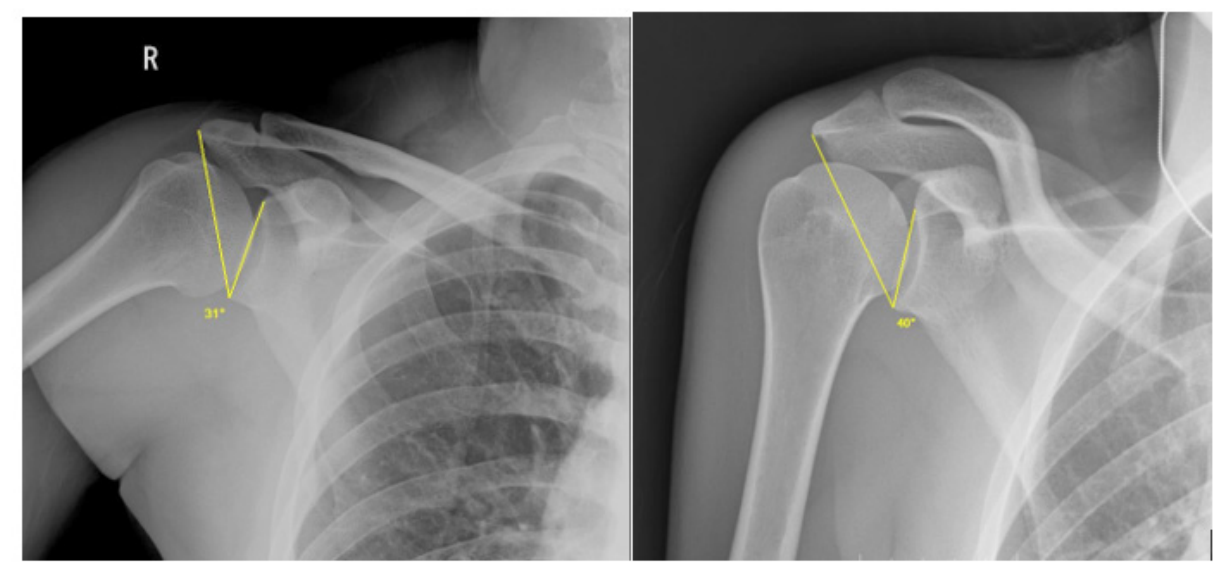

Figure 1: Critical Shoulder Angle: the angle formed by the line connecting the superior to the inferior most aspect of the glenoid and a second line extending from the inferior glenoid to the inferolateral aspect of the acromion.

Numerous studies have found that radiographic CSA measurements have a very high interobserver and inter-observer reliability [7-9], as high as $96.7 \%$ interobserver and 95.5\% interobserver reproducibility [9]. Bouaicha et al. [10] compared CSA angle measurements between radiographs and computerized topography (CT). They measured the CSA on radiographs as originally defined by Moor et al. [6] and compared these to the measurements produced by 64-slice CT with three-dimensional reconstruction of the scapula. It was shown that AP radiographs and CT measurements of the CSA do not differ significantly and were 
both reliable methods of evaluating the CSA. In the measurement of the CSA, comparing radiographs to magnetic resonance imaging, radiographs have been shown to be more reliable than MRI [11].

Scapular position has been shown to affect the CSA measurement enough to potentially alter the clinical interpretation and its reproducibility $[6,12,13]$. Moor [6] determined that CSA measurements deviated $<2^{\circ}$ with scapular malrotation up to $20^{\circ}$ in internal rotation/extension and $20^{\circ}$ in external rotation/ flexion. These tolerances were modified by Suter et al. [13] with the addition of scapular version, indicating that $5^{\circ}$ anteversion, $8^{\circ}$ retroversion, $>15^{\circ}$ flexion, and $>26^{\circ}$ extension led to a $2^{\circ}$ or greater change in the CSA and should be avoided. This led to the development of the Suter-Henninger (SH) scapular classification system [13], which reliably measures and detects mispositioning of the scapula on the AP radiograph. This system classifies the glenoid rim overlap as Type A-D, where Type A has no overlap and Type D has a double contour of the glenoid rim $>50 \%$ of the glenoid height. It further classifies coracoglenoid overlap as Type 1-3 coracoid overlap with the upper glenoid rim is classified as Type 1 while no coracoid overlap with upper rim of glenoid because the coracoid projection is inferior to the upper glenoid rim is classified as Type 3. Radiographs with Type B (inverted tear drop at the upper glenoid rim) or Type D (any glenoid double contour $>50 \%$ of glenoid height) rotation were determined to be malpositioned enough to distort the CSA measurement in a clinically relevant way and should not be used to calculate the CSA [13].

\section{CSA, glenohumeral arthritis and rotator cuff tears}

Moor et al. [6] originally described the CSA in three groups. They had found that shoulders with a CSA $<30^{\circ}$ had an increased prevalence of glenohumeral arthritis, those with a CSA $>35^{\circ}$ had a higher prevalence of RCT, and those with a CSA $30-35^{\circ}$ had significantly lower rates of both glenohumeral arthritis and RCT. Similar findings were produced by several other authors [14-16] and an elevated CSA has also been found to be an independent risk factor for full-thickness RCT [17].

The biomechanical association between CSA and shoulder pathology involves the force vector generated by the deltoid during contraction and the impact of this vector on adjacent shoulder structures. Gerber et al. [18] showed that when the CSA increased from $33^{\circ}$ to $38^{\circ}$, there was a $13-33 \%(15-23 N)$ increase in supraspinatus strain during thoracohumeral abduction; max strain was reached during $33^{\circ}$ to $37^{\circ}$ of abduction. The more lateral deltoid origin seen with an elevated CSA increases the shear forces on the supraspinatus tendon, thus increasing its strain. This increase in shear forces also results in glenohumeral instability (higher shear forces, lower compressive forces), requiring more force from the rotator cuff muscles to maintain stability of the joint [19-23], which in turn leads to rotator cuff pathology as well as eccentric wear of the glenoid articular surface [24].

Furthermore, Mantell et al. [25] found a significant increase in concurrent OA and RCT in shoulders with CSA $>35^{\circ}$ (90\% specific, $52 \%$ sensitive) and recommended using this measurement as a screening tool, directing the need for MRI when managing patients with osteoarthritis. Cherchia et al. [9] not only found an association with RTC pathology and CSA but were also able correlate increased CSA with labral tears requiring repair. Blonna et al. [12] correlated a CSA of $\geq 36^{\circ}$ with an increased risk for RCT, increased size of the tear and eccentric glenohumeral arthritis while a CSA of $\leq 28^{\circ}$ was correlated with concentric glenohumeral arthritis.

Several studies have failed to show an association between increased CSA and rotator cuff pathology. Bjarnison et al. [26] found a positive association between $\mathrm{OA}$ and CSA below $30^{\circ}$, but did not find a strongly positive association with elevated CSA and RCT. Similarly, Chalmers et al [27] did not find a correlation between elevated CSA and rotator cuff pathology, however both Chalmers and Bjarnison were unable to achieve a mean CSA $>35^{\circ}$ (Bjanrison RCT group mean CSA $33.6^{\circ}$, Chalmers RCT group mean CSA $34^{\circ}$ ) $[26,27]$ as originally described by Moor et al. [6].

\section{Acromioplasty and the CSA}

In cadaver studies, the CSA was able to be altered without violation of the deltoid insertion. Alitnta et al. [28] were able to arthroscopically resect $1 \mathrm{~cm}$ of the lateral acromion, reducing the mean CSA from $35.0^{\circ}$ to $25.1^{\circ}$, without any evidence of deltoid violation. Katthagen et al. [29] used an arthroscopic anterolateral acromioplasty to reduce the CSA by a mean of $1.4^{\circ}$ and were able to achieve a $2.8^{\circ}$ reduction in CSA when combined with a $5 \mathrm{~mm}$ lateral acromion resection. They determined combined arthroscopic acromioplasty with lateral acromial resection to be a feasible procedure capable of reducing the CSA without damage to the deltoid origin. Furthermore, Milano recommended lateral acromioplasty as a safe and effective procedure to reduce the CSA without violating the acromial deltoid origin this is a potentially useful procedure to prevent progression of RCT or to protect a cuff repair from re-tear [30]. However, there is currently not much literature pertaining to the intermediate and long-term outcomes of lateral acromioplasty and the complications following overresection.

In the current literature, it is unknown whether a reduction of the CSA with lateral acromioplasty to within the normal accepted range of $30-35^{\circ}$ decreases the incidences of primary RCTs or retears after RCT repair. Of note, it has been shown that patients with impingement who underwent arthroscopic subacromial decompression with acromioplasty had a decreased long-term prevalence of rotator cuff tears [31]. However, this study did not include data on the change in CSA, while Familiari et al. [32] in a systematic literature review found no difference in shortterm clinical outcomes in patients undergoing rotator cuff repair with and without acromioplasty and did not recommend routine acromioplasty during rotator cuff repairs.

\section{Outcomes}

Preoperative CSA has been shown to be a risk factor complicating arthroscopic rotator cuff repair. A retrospective study conducted by Garcia et al. [33] found high preoperative CSA ( $\geq 38^{\circ}$ ) to be associated with a 14-fold increased risk in full thickness retear after RCT repair as well as worse postoperative American Shoulder and Elbow Surgeons scores at short-term follow-up. Furthermore, Gerber et al. [34] determined that smaller CSAs 
were associated with better long-term postoperative clinical and functional outcomes after irreparable posterosuperior RCTs which were treated with latissimus dorsi tendon transfers. On the other hand, Lee et al. [35] found patients with lower CSAs to have better functional scores at 6 months but found no difference in functional outcome scores at 24 month follow-up. Kirsch et al. [36] concluded in their study of 53 patients that those with a CSA $>38$ degrees showed no significant difference in postoperative functional or pain scores.

Following hemiarthroplasty, Cerciello et al. [37] found no association between CSA and symptomatic glenoid erosion at 105 month follow-up. In another study, CSA was not associated with late rotator cuff failure following anatomic shoulder replacement with a mean follow-up of 45 months [38]. Hemiarthroplasty following fracture [39], however, has been shown to impart poorer functional outcomes and pain scores at long-term follow-up 53 months in patients with CSA $>38^{\circ}$.

\section{Summary}

As described by Moor et al. [6] the CSA is a reliable measurement of the extent of acromial lateral projection which has high intraobserver and inter-observer reproducibility. While a true scapular anterior posterior radiograph is the gold standard for this measurement a 3D reconstructed $\mathrm{CT}^{10}$ may also be used with similar reliability. Several studies have repeated and confirmed that Moor's original clinical implications of this radiographic measure are accurate a low $\operatorname{CSA}\left(<30^{\circ}\right)$ is associated with glenohumeral concentric osteoarthritis and a high CSA $\left(>35^{\circ}\right)$ is associated with full-thickness RCTs, eccentric glenohumeral osteoarthritis and is an independent risk factor for rotator cuff pathology [6,14-16].

Lateral acromioplasty has been shown to be capable of reducing a high CSA below the $35^{\circ}$ threshold without disrupting the deltoid insertion [29], which may be useful preventing progression or recurrence of rotator cuff pathology. There is, however, very little literature examining the clinical and functional outcomes following a lateral acromioplasty and debate still exists on whether this procedure's benefit is clinically relevant or merely theoretical.

Future research may look to address the gaps in literature surrounding effectiveness of lateral acromioplasty in preventing repeat rotator cuff pathology and the need for revision surgery. There may also be a place for research related to the impact of CSA on the outcomes of reverse total shoulder arthroplasty.

\section{Disclosures}

This review article was produced by members of the Department of Orthopedics at Nassau University Medical Center, East Meadow NY. There are no conflicts of interest or financial disclosures to report. There were no external sources of funding for this project.

\section{References}

1. Armstrong JR (1949) Excision of the acromion in treatment of the supraspinatus syndrome: report of 95 excisions. J Bone Joint Surg $\mathrm{Br}$ 31(3): 436-442.

2. Neer CS (1972) Anterior acromioplasty for the chronic impingement syndrome in the shoulder. A preliminary report. J Bone Joint Surg 54(1): 41-50.

3. Bigliani LU, Morrison DS, April EW (1986) The morphology of the acromion and its relationship to rotator cuff tears. Orthop Trans 10: 216.

4. Banas MP, Miller RJ, Totterman S (1995) Relationship between the lateral acromion angle and rotator cuff disease. J Shoulder Elbow Surg 4(6): 454-461.

5. Nyffeler RW, Werner CM, Sukthankar A, Schmid MR, Gerber C (2006) Association of a large lateral extension of the acromion with rotator cuff tears. J Bone Joint Surg Am 88(4): 800-805.

6. Moor BK, Bouaicha S, Rothenfluh DA, Sukthankar A, Gerber C (2013) Is there an association between the individual anatomy of the scapula and the development of rotator cuff tears or osteoarthritis of the glenohumeral joint? A radiological study of the critical shoulder angle. Bone Joint J 95(7): 935-941.

7. Cerciello S, Monk AP, Visona E, Carbone S, Edwards TB, et al. (2017) The influence of critical shoulder angle on secondary rotator cuff insufficiency following shoulder arthroplasty. Arch Orthop Trauma Surg 137(1): 913-918.

8. Cerciello S, Morris BJ, Visona E, Corona K, Edwards TB, et al. (2017) No relationship between critical shoulder angle and glenoid erosion after shoulder hemiarthroplasty: a comparative radiographic study. Arch Orthop Trauma Surg 137(7): 919-923.

9. Cherchia L, Ciornohaca JF, Godetb J, Claverta P, Kempfa JF (2016) Critical shoulder angle: Measurement reproducibility and correlation with rotator cuff tendon tears. Orthopaedics \& Traumatology. Surgery \& Research 102: 559-562.

10. Bouaicha S, Ehrmann C, Slankamenac K, Regan WD, Moor BK (2014) Comparison of the Critical Shoulder Angle in Radiographs and Computed Tomography. Skeletal Radiology 43(8):1053-1056.

11. Spiegl UJ, Horan MP, Smith SW, Ho CP, Millett PJ (2016) The Critical Shoulder Angle Is Associated with Rotator Cuff Tears and Shoulder Osteoarthritis and Is Better Assessed with Radiographs over MRI. Knee Surg Sports Traumatol Arthrosc 24(7): 2244-2251.

12. Blonna D, Giani A, Bellato E, Mattei L, Caló M, et al. (2016) Predominance of the critical shoulder angle in the pathogenesis of degenerative diseases of the shoulder. J Shoulder Elbow Surg 25:1328-1236.

13. Suter T, Gerber Popp A, Zhang Y, Zhang C, et al. (2015) Henninger HB. The Influence of Radiographic Viewing Perspective and Demographics on the Critical Shoulder Angle. J Shoulder Elbow Sur 24(6): 149-158.

14. Ulrich J, Spiegl UJ, Horan MP, Smith SW, Ho CP, et al. (2016) The critical shoulder angle is associated with rotator cuff tears and shoulder osteoarthritis and is better assessed with radiographs over MRI. Knee Surg Sports Traumatol Arthrosco 24: 2244-2251.

15. Pandey V, Vijayan D, Tapashetti S, Agarwal L, Kamath A, et al. (2016) Does scapular morphology affect the integrity of the rotator cuff? J Shoulder Elbow Surg 25(3): 413-421.

16. Gomide LC, Correa do CT, Moreira BGH, Oliveira GA, Macedo IS (2017) Relationship between the critical shoulder angle and the development of rotator cuff lesions: a retrospective epidemiological study. Rev Bras Orthop 52(40): 423-427.

17. Moor BK, Röthlisberger M, Müllera DA, Zumsteinb MA, Bouaichac S, et al. (2014) Age, trauma and the critical shoulder angle accurately predict supraspinatus tendon tears. Orthopaedics \& Traumatology. Surgery \& Research 100: 489-494.

18. Gerber C, Snedeker JG, Baumgartner D, Viehofer AF (2014) Supraspinatus Tendon Load During Abduction Is Dependent on the Size of the Critical Shoulder Angle: A Biomechanical Analysis. J Orthop Res 32: 952-957.

19. Viehofer AF, Gerber C, Favre P, Bachmann E, Snedeker JG (2016) A Larger Critical Shoulder Angle Requires More Rotator Cuff Activity to Preserve Joint Stability. J Orthop Res 34: 961-968. 
20. Favre P, Senteler M, Hipp J (2012) An integrated model of active glenohumeral stability. J Biomech 45: 2248-2255.

21. Lazarus MD, Sidles JA, Harryman DT, Matsen FA (1996) Effect of a chondral-labral defect on glenoid concavity and glenohumeral stability. A cadaveric model. J Bone Joint Surg Am 78: 94-102.

22. Fukuda K, Chen CM, Cofield RH, Chao EY (1988) Biomechanical analysis of stability and fixation strength of total shoulder prostheses. Orthopedics 11: 141-149.

23. Lippitt S, Matsen F (1993) Mechanisms of glenohumeral joint stability. Clin Orthop Relat Res 291: 20-28.

24. Blonna D, Giani A, Bellato E, Mattei L, Caló M, et al. (2016) Predominance of the critical shoulder angle in the pathogenesis of degenerative diseases of the shoulder. J Shoulder Elbow Surg 25: 1328-1336.

25. Mantell MT, Nelson R, Lowe JT, Endrizzi DP, Jawa A (2017) Critical shoulder angle is associated with full-thickness rotator cuff tears in patients with glenohumeral osteoarthritis. J Shoulder Elbow Surg 26(12): 376-381.

26. Bjarnison AO, Soresnen TJ, Kellemose T, Barfod K (2017) The critical shoulder angle is associated with osteoarthritis in the shoulder but no rotator cuff tears: a retrospective case-control study. J Shoulder Elbow Surg 26(12): 2097-2102

27. Chalmers PN, Salazar D, Steger MK, Chamberlain AM, Yamaguchi K, et al. (2017) Does the critical shoulder angle correlate with rotator cuff tear progression? Clin Orthop Relat Res 475: 1608-1617.

28. Alitnta B, Kaab M, Greiner S (2016) Arthroscopic lateral acromion resection (ALAR) optimizes rotator cuff tear relevant scapula parameters. Arch Orthop Trauma Surg 136(6): 799-804.

29. Katthagen JC, Marchetti DC, Tahal DS, Turnbull TL, Millett PJ (2016) The effects of arthroscopic lateral acromioplasty on the critical shoulder angle and the anterolateral deltoid origin: an anatomic cadaveric study. Arthroscopy 32: 569-575.

30. Milano G (2016) Editorial Commentary: Is Lateral Acromioplasty Effective and Safe? Arthroscopy 32(4): 576-577.
31. Bjoernsson H, Norlin R, Knutsson A, Adolfsson L (2010) Fewer rotator cuff tears fifteen years after arthroscopic subacromial decompression. J Shoulder Elbow Surg 19: 111-115.

32. Familiari F, Gonzalez ZA, Iannò B, Galasso O, Gasparini G, et al. (2015) Is acromioplasty necessary in the setting of full-thickness rotator cuff tears? A systematic review. J Orthop Traumatol 16: 167-174.

33. Garcia GH, Liu JN, Degen RM, Johnson CC, Wong A, et al. (2017) Higher critical shoulder angle increases the risk of retear after rotator cuff repair. J Shoulder Elbow Surg 26(2): 241-245.

34. Gerber C, Rahm SA, Catanzaro S, Farshad M, Moor BK (2013) Latissimus dorsi tendon transfer for treatment of irreparable posterosuperior rotator cuff tears: Long-term results at a minimum follow-up of ten years. J Bone Joint Surg Am 95: 1920-1926.

35. Lee M, Chen JY, Liow MHL, Chong HC, Chang P, et al. (2017) Critical shoulder angle and acromial index do not influence 24-month functional outcome after arthroscopic rotator cuff repair. Am J Sports Med 45(13): 2989-2994.

36. Kirsch JM, Nathani A, Robbins CB, Gagnier JJ, Bedi A (2017) Is there an association between the "Critical Shoulder Angle" and Clinical outcome after rotator cuff repair? Orthop J Sports Med 5(4).

37. Cerciello S, Morris BJ, Visona E, Corona K, Edwards TB, et al. (2017) No relationship between critical shoulder angle and glenoid erosion after shoulder hemiarthroplasty: a comparative radiographic study. Arch Orthop Trauma Surg 137(7): 919-923.

38. Cerciello S, Monk AP, Visona E, Carbone S, Edwards TB (2017) The influence of critical shoulder angle on secondary rotator cuff insufficiency following shoulder arthroplasty. Arch Orthop Trauma Surg 137(1): 913-918.

39. Park YK, Kim SH, Oh JH (2017) Intermediate-term outcome of hemiarthroplasty for comminuted proximal humerus fractures. J Shoulder Elbow Surg 26(1): 85-91.
Creative Commons Attribution 4.0 International License

For possible submissions Click Here
Submit Article

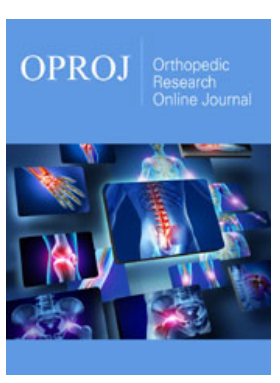

Orthopedic Research Online Journal

Benefits of Publishing with us

- High-level peer review and editorial services

- Freely accessible online immediately upon publication

- Authors retain the copyright to their work

- Licensing it under a Creative Commons license

- Visibility through different online platforms 